\title{
The occurrence of sclerotium rot on Catharanthus roseus caused by Sclerotium rolfsii in South Korea
}

\author{
Jin-Hyeuk Kwon • Dong-Wan Kang • Shun-Shan Shen • \\ Jinwoo Kim
}

Received: 12 June 2014 / Accepted: 5 August 2014 / Published online: 10 August 2014

(C) Australasian Plant Pathology Society Inc. 2014

\begin{abstract}
In May 2013, an occurrence of sclerotium rot was observed on rosy periwinkle (Catharanthus roseus) plants grown in a seedling greenhouse in Jinju, South Korea. The typical symptoms included blighting and rotting, and severely infected plants eventually died. Furthermore, mycelial mats spread over the infected rosy periwinkle stems and leaves and sclerotia formed near the soil surface. On the basis of the morphological characteristics, the complete internal transcribed spacer (ITS) ribosomal RNA gene sequence analysis, and pathogenicity tests, the causal fungus was identified as Sclerotium rolfsii Saccardo. This is the first report of sclerotium rot caused by $S$. rolfsii on rosy periwinkle in South Korea.
\end{abstract}

Keywords Sclerotium rolfsii · Sclerotium rot · Rosy periwinkle $\cdot$ rDNA spacer sequence

Rosy periwinkle [Catharanthus roseus (L.) G. Don] is a popular ornamental plant found in gardens and homes across the subtropical and tropical areas of the world (Wikipedia Foundation). It is also known as the source of terpenoid indole alkaloids, many of which are pharmaceutically important (Zhou et al. 2009; Aslam et al. 2010). In South Korea, rosy periwinkle is cultivated as a flowering evergreen ornamental plant. In May 2013, an occurrence of sclerotium rot was observed on rosy

J.-H. Kwon · D.-W. Kang

Gyeongsangnam-do Agricultural Research and Extension Services,

Jinju 660-360, South Korea

S.-S. Shen

College of Plant Protection, Henan Agricultural University,

Zhengzhou 450002, China

J. $\operatorname{Kim}(\square)$

Division of Applied Life Science (BK21 Plus) and Institute of Agriculture and Life Science, Gyeongsang National University, Jinju 660-701, South Korea

e-mail: jinwoo@gnu.ac.kr periwinkle in a greenhouse in Jinju, South Korea. The rot was most developed on stems and leaves near the soil line, and infected rosy periwinkle plants eventually withered and died. White mycelial mats and numerous sclerotia were produced on stems and leaves near the soil surface (Fig. 1a).

Five diseased stems of rosy periwinkle plants were sampled, and fungal isolations were performed on potato dextrose agar (PDA) as described previously (Kwon et al. 2012). Briefly, pieces of diseased leaves of rosy periwinkle were dissected, subjected to surface-disinfection with $1 \%$ sodium hypochlorite solution for $1 \mathrm{~min}$, rinsed with sterilized distilled water and then air-dried. The air dried pieces were placed on PDA and incubated at $25^{\circ} \mathrm{C}$ for 2 days. Mycelial tips of the fungal isolates grown on PDA were transferred to new PDA. Five isolates of Sclerotium sp. were recovered from diseased plant samples. The mycelium growth rate of all fungal isolates was determined by propagation on PDA at different temperatures $\left(20,25,30,35\right.$, and $\left.40{ }^{\circ} \mathrm{C}\right)$, with the optimum temperature for growth determined as $30^{\circ} \mathrm{C}$. Aerial mycelia usually formed many narrow hyphal strands 4-9 $\mu \mathrm{m}$ wide. Sclerotia (1-3 mm) were white at first, and then turned dark brown (Fig. 1b); white mycelium formed typical clamp connections after 5 days of growth at $30^{\circ} \mathrm{C}$ (Fig. 1c). The measurements and taxonomic characteristics coincided with those of Sclerotium rolfsii Saccardo described previously (Mordue 1974). One of the representative fungal isolates has been deposited with the Korean Agricultural Culture Collection (KACC 47749), National Academy of Agricultural Science, Rural Development Administration, Suwon, South Korea.

To test pathogenicity, inoculum of a representative fungal isolate (KACC 47749) was prepared as previously described (Kwon et al. 2012). The 7-day-old PDA culture of the test fungus was used in soil inoculum. The harvested mycelial mats including sclerotia from 30 petri dishes $(9 \mathrm{~cm}$ in diameter) was mixed thoroughly with $3 \mathrm{~kg}$ of sterilized soil, and the soil mixture was used as an inoculum; $100 \mathrm{~g}$ soil inoculum 
Fig. 1 Symptoms of sclerotium rot on rosy periwinkle (Catharanthus roseus) of the pathogenic fungus Sclerotium rolfsii: a infected plants showing typical symptoms on leaves. Mycological characteristics of the pathogenic fungus Sclerotium rolfsii: $\mathbf{b} S$. rolfsii on potato dextrose agar after 20 days of incubation; c clamp connection (arrow), bar $=10 \mu \mathrm{m}$

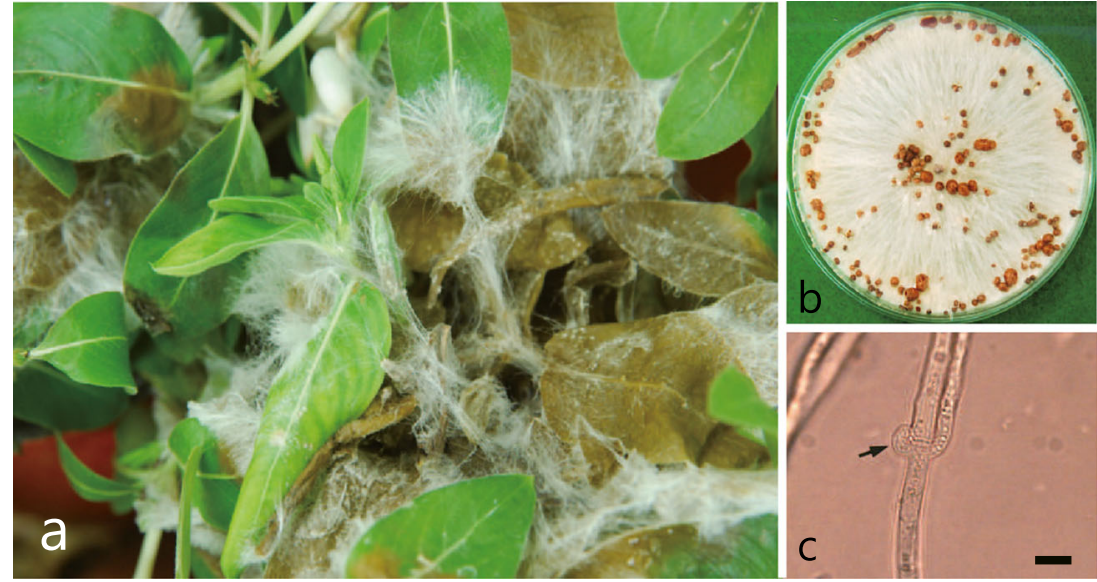

was placed on top of the soil in pots $(10 \times 10 \times 8 \mathrm{~cm})$, after which nine 1-month-old rosy periwinkle plants were transplanted into each pot. Three pots containing noninfested soil inoculum were used as negative controls. All pots were kept separately in a greenhouse and observed for symptom development. Symptoms started 4 days after inoculation, the same disease symptoms as those witnessed in the greenhouse developed within 12 days after inoculation on $100 \%$ of the inoculated plants, whereas, no symptoms developed on the negative control plants. The fungus was re-isolated from inoculated plants, fulfilling Koch's postulates.

To confirm the identity of the causal fungus, the complete internal transcribed spacer (ITS) rDNA of a representative fungal isolate (KACC 47749) was amplified using primers ITS1 (5'-TCCGTAGGTGAACCTGCGG-3') and ITS4 (5'TCCTCCGCTTATTGATATGC-3') (White et al. 1990). Total DNA was isolated using the Exgene Plant-Fungal SV Mini Kit (Geneall Biotechnology Co., Seoul, South Korea), following the manufacturer's instructions. The polymerase chain reaction (PCR) mixture contained 5 units Taq polymerase (TaKaRa, Tokyo, Japan), $1 \times$ PCR buffer, $0.2 \mathrm{mM}$ of each
dNTP, 5 pmol of each primer, and approximately $10 \mathrm{ng}$ fungal genomic DNA with the total volume adjusted to $50 \mu \mathrm{l}$ with sterile water. PCR was performed using a thermal cycler (PC 802; Astec, Fukuoka, Japan) with the following thermal profile: $98^{\circ} \mathrm{C}$ for $2 \mathrm{~min}$, followed by 30 cycles at $98^{\circ} \mathrm{C}$ for $30 \mathrm{~s}$, $60{ }^{\circ} \mathrm{C}$ for $30 \mathrm{~s}, 70{ }^{\circ} \mathrm{C}$ for $30 \mathrm{~s}$, and a final extension step at $72{ }^{\circ} \mathrm{C}$ for $4 \mathrm{~min}$. Amplified products were separated by electrophoresis on a $0.8 \%$ agarose gel in $1 \times$ Tris-borate-EDTA (TBE) buffer at $50 \mathrm{~V}$ for $20 \mathrm{~min}$. The PCR amplicons were extracted after agarose gel electrophoresis using a gel extraction kit (Geneall Biotechnology Co.), and purified PCR products were cloned into the pGEM-T Easy Vector (Promega, Madison, WI, USA). The resulting plasmid clone (pOR148) that contained an insert of the expected size was withheld, and its insert was sequenced in both directions with the primers M13F and M13R at Macrogen Services (Seoul, South Korea). The resulting $684 \mathrm{bp}$ of ITS rDNA sequence was deposited in GenBank (Accession No. KJ944396). The nucleotide sequence of the ITS rDNA region obtained was compared with those of reported ITS sequences in the NCBI nucleotide database for reference. The sequences were additionally analyzed
Fig. 2 Phylogenetic tree produced using internal transcribed spacer sequences, showing the closest known relatives of Sclerotium rolfsii. DNA sequences from the NCBI nucleotide database were aligned using ClustalW, and a phylogenetic tree was constructed using the neighbor-joining method, visualized with TreeView. The numbers above branches indicate bootstrap values. Bars indicate the number of nucleotide substitutions per site. The isolate studied in the present study is marked in bold. Host plants are given in parentheses

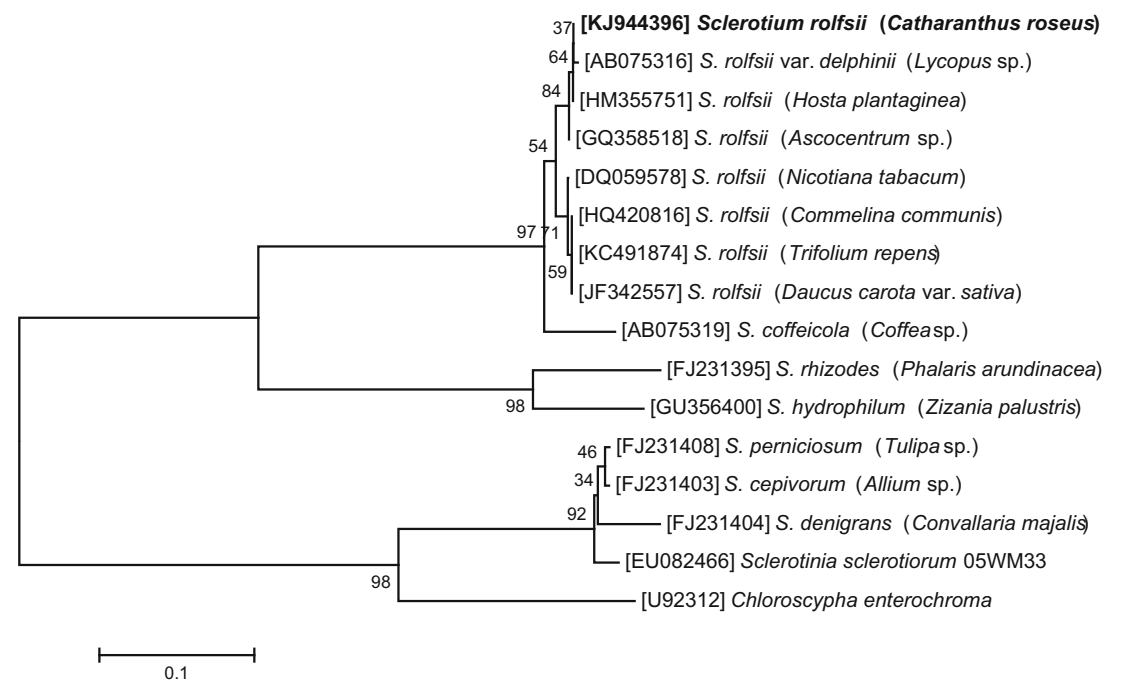


using the Basic Local Alignment Search Tool (BLAST) program (http://www.ncbi.nlm.nih.gov/). The nucleotide sequence was exactly matched with sequences (GenBank Accession No. HM355751) of S. rolfsii (Kwon et al. 2010).

Phylogenetic analysis was performed using MEGA4 (http://www.megasoftware.net/) software employing the neighbor-joining method and the Tajima-Nei distance model (Tamura et al. 2007). The multiple sequence alignment of the ITS rDNA region was carried out using the ClustalW software. Previously published ITS sequences of $S$. rolfsii strains were included for reference, and Chloroscypha enterochrom (GenBank Accession No. U92312) was used as an outgroup (Xu et al. 2010). The fungus isolated from rosy periwinkle was placed within a clade comprising reference isolates of $S$. rolfsii (Fig. 2).

Thus, on the basis of the symptoms, morphological characteristics, the complete ITS sequence analysis, and pathogenicity assays, this fungus was identified as Sclerotium rolfsii Saccardo (Mordue 1974). To the best of our knowledge, this is the first report of sclerotium rot on rosy periwinkle caused by S. rolfsii in South Korea. The recent occurrence of the disease in rosy periwinkle in a seedling greenhouse suggests that sclerotium rot is spreading widely and posing serious threats to its nursery business in South Korea.

Acknowledgments This work was carried out with the support of the "Cooperative Research Program for Agriculture Science \& Technology Development (Project No. PJ009192)" Rural Development Administration, Korea.

\section{References}

Aslam J, Khan SH, Siddiqui ZH, Fatima Z, Maqsood M, Bhat MA, Nasim SA, Ilah A, Ahmad IZ, Khan SA, Mujib A, Sharma MP (2010) Catharanthus roseus (L.) G. Don. An important drug: it's applications and production. Pharmacie Globale (IJCP) 4: $1-16$

Kwon JH, Chi TTP, Kim J (2010) First report of stem rot on Hosta plantaginea caused by Sclerotium rolfsii in Korea. Plant Pathol J 26:297

Kwon JH, Kim J, Lee YH, Shim HS (2012) Sclerotium rot of sponge gourd caused by Sclerotium rolfsii. Res Plant Dis 18: $54-56$

Mordue JE (1974) Corticium rolfsii. CMI descriptions of pathogenic fungi and bacteria. No. 410. Surrey: Commonwealth Mycological Institute

Tamura K, Dudley J, Nei M, Kumar S (2007) MEGA4: Molecular Evolutionary Genetics Analysis (MEGA) software version 4.0. Mol Biol Evol 24:1596-1599

White TJ, Bruns T, Lee S, Taylor JW (1990) Amplification and direct sequencing of fungal ribosomal RNA genes for phylogenetics. In: Innis MA, Gelfand DH, Sninsky JJ, White TJ (eds) PCR protocols: a guide to methods and applications. Academic, San Diego, pp 315-322

Wikipedia Foundation Inc. http://en.wikipedia.org/wiki/Catharanthus roseus\#cite_ref-rhs_11-0 (accessed 13 July, 2014)

Xu Z, Harrington TC, Gleason ML, Batzer JC (2010) Phylogenetic placement of plant pathogenic Sclerotium species among teleomorph genera. Mycologia 102:337-346

Zhou ML, Shao JR, Tang YX (2009) Production and metabolic engineering terpenoid indole alkaloids in cell cultures of the medicinal plant Catharanthus roseus (L.) G. Don (Madagascar periwinkle). Biotechnol Appl Biochem 52:313-323 